\title{
Farmers' attitude toward the introduction of selective dry cow therapy
}

\author{
C. G. M. Scherpenzeel, ${ }^{* 1}$ S. H. W. Tijs, ${ }^{*}$ I. E. M. den Uijl, ${ }^{*}$ I. M. G. A. Santman-Berends, ${ }^{*}$ A. G. J. Velthuis, ${ }^{*}$ \\ and T. J. G. M. Lam*† \\ ${ }^{*}$ GD Animal Health, PO Box 9, 7400 AA Deventer, the Netherlands \\ †Utrecht University, Department Farm Animal Health, PO Box 80151, 3508 TD Utrecht, the Netherlands
}

\section{ABSTRACT}

The attitude of Dutch dairy farmers toward selective dry cow treatment (SDCT) is unknown, although a favorable mindset toward application of SDCT seems crucial for successful implementation. Given the fact that blanket dry cow treatment has been strongly promoted until recently, the implementation of SDCT was expected to be quite a challenge. This study aimed to provide insight into the level of implementation of SDCT in 2013 in the Netherlands, the methods used by farmers for selection of cows for dry cow treatment (DCT), the relation between SDCT and udder health and antimicrobial usage (AMU) in 2013, and the mindset of farmers toward SDCT. In 2014, a questionnaire was conducted in a group of 177 herds included in a large-scale udder health study in 2013 and for which all clinical mastitis cases during this year were recorded. In addition, data on somatic cell count (SCC) parameters and AMU was available for these herds. The questionnaire included questions with regard to DCT with a special emphasis on farmers' attitude and mindset with regard to applying DCT in 2013. The data that were obtained from the questionnaire were combined with the data on clinical mastitis, SCC, and AMU. Descriptive statistics were used to evaluate the data and to study the association between DCT, udder health, and AMU. Univariable and multivariable logistic regression models with a logit link function were applied to evaluate potential associations between DCT and farmers' mindset. Selective DCT was taken up progressively by the farmers in our study, with $75 \%$ of them implementing SDCT in 2013. The main criterion used to select cows for DCT was the SCC history during the complete previous lactation. The herds were divided into 3 groups based on the percentage of cows dried

Received April 22, 2016.

Accepted June 13, 2016

${ }^{1}$ Corresponding author: c.scherpenzeel@gdanimalhealth.com off with antibiotics in 2013 as indicated by the farmers during interviews. The first group applied BDCT, and the herds for which SDCT was applied were split in 2 equally sized groups based on the median percentage of cows dried off with antibiotics (67\%). The incidence rate of subclinical and clinical mastitis were comparable between the groups. Results of the multivariable model showed that 4 factors related to farmers' mindset were associated with the probability to apply SDCT: "financial consequences of SDCT," "uncertainty whether a cow will recover without antimicrobials," the statement "I do not have a problem with the (potential) negative consequences of SDCT," and the usage of internal teat sealants. Application of SDCT appeared to be associated with farmers' attitude. The mindset of farmers with respect to reduction of AMU and the implementation of SDCT was generally positive.

Key words: antimicrobials, udder health, selective dry cow therapy, attitude

\section{INTRODUCTION}

Use of antimicrobials for treatment of bacterial infections in both humans and food-producing animals can lead to decreased antimicrobial susceptibility (Chantziaras et al., 2014) and is a concern of the general public in many countries (Freimuth et al., 2000). Although the relationship between antimicrobial use (AMU) and the development of antimicrobial resistance (AMR) in bacteria is complex and unclear (Oliver et al., 2011), a relation between veterinary AMU and veterinary AMR is likely (Chantziaras et al., 2014).

Antimicrobials in dairy are mainly used for treatment of clinical mastitis (CM) and dry cow treatment (DCT). For many years, approximately $60 \%$ of the AMU in dairy cattle was related to mastitis, of which roughly two-thirds was related to DCT (Kuipers et al., 2016). Blanket dry cow therapy (BDCT), an approach to treat every quarter of every cow at drying-off with antibiotics, is common practice in many countries in the world including, until recently, the Netherlands (Sampimon et al., 2008). In the Netherlands, however, 
preventive use of antimicrobials in animal husbandry has been prohibited since 2013, and BDCT is no longer allowed. Since then, farmers have been using selective DCT (SDCT). No guidelines were available on how to select animals for DCT. Nevertheless, most farmers implemented a form of SDCT according to their own criteria (Santman-Berends et al., 2016). In January 2014, the Royal Dutch Veterinary Association launched guidelines to be used when implementing SDCT (KNMvD, 2014).

The attitude of Dutch dairy farmers toward SDCT is unknown, although a favorable mindset toward application of SDCT seems crucial for successful implementation. Several studies describe the huge influence of the mindset of farmers on udder health (Lam et al., 2011; Jones et al., 2015). Given that BDCT has been strongly promoted until recently (Lam et al., 2013), the implementation of SDCT was expected to be quite a challenge.

This study aimed to provide insight into the level of implementation of SDCT in 2013 in the Netherlands, the methods used by farmers for selection of cows for $\mathrm{DCT}$, the relation between SDCT and udder health and AMU in 2013, and the mindset of farmers toward SDCT.

\section{MATERIALS AND METHODS}

\section{Study Population}

In 2012, a random selection of 1,352 Dutch dairy farmers were contacted by mail to participate in a study on CM occurrence (Santman-Berends et al., 2015, 2016). Conventional farms with a traditional milking system (no automatic milking system) that participated in a milk recording program on a 4- to 6-wk interval (Dutch Royal Cattle Syndicate CRV, Arnhem, the Netherlands), including SCC measurement, were eligible for inclusion. Farmers representing a total of 233 dairy herds participated in this study and completed the requested registration.

Farmers were asked to observe and register all $\mathrm{CM}$ cases in their herd and to communicate these data on a monthly basis from January 1 to December 31, 2013. The participating farmers were instructed on the definition of $\mathrm{CM}$ and the recording procedure. They also gave consent for the use of their routinely collected data, which included data on cow identification and registration (I\&R, provided by the Dutch Enterprise Agency RVO, The Hague, the Netherlands), data on AMU (ZuivelNL, The Hague, the Netherlands), SCC data on bulk tank level (BTSCC; Qlip Laboratories, Zutphen, the Netherlands), and on cow-level (CRV, Arnhem, the Netherlands).

\section{Survey Questionnaire}

Data regarding implementation of SDCT and the mindset of the farmer toward AMU and SDCT were collected using a detailed questionnaire that contained demographic items about the herds, items about implementation of DCT in 2013, and items on the attitude toward AMU and DCT. The questionnaire consisted of open questions, questions with predefined answer categories, and statements that the farmers were asked to rate on a 5-point Likert scale (Likert, 1932). To find out which aspects of reduction of AMU were perceived as being the most important, farmers were asked to mention positive and negative aspects and to rank them without using predefined answer categories. Subsequently, the interviewer categorized the answers in defined categories or created a new category as needed.

The questionnaire was pretested on completeness, wording, and time needed to complete by 2 farmers, and their feedback was incorporated in the final version. Three interviewers were trained to ask the questions in a similar way. The interviewee was the person who was responsible for dry cow management in the herd. Careful attention was given to asking the questions in an open manner to prevent socially desirable answering instead of true opinions. Additionally, it was clearly stated at the start of each interview that the answers provided by the farmers would be analyzed summed over herds, the answers would be presented anonymously, and it would not be possible to trace any answer back to an individual farmer. The questionnaires were conducted by telephone between April 17 and May 16, 2014.

The calculations for the udder health parameters that were evaluated are described in Santman-Berends et al. (2016). In short, the incidence rate of CM (IRCM) was calculated as the number of cases per 100 cows at risk per year in 2013. Clinical mastitis was defined as every abnormality of udder, milk, or both as observed by the farmer. Abnormalities included alteration in color or texture of the milk and swollen or red quarters with or without systemic clinical signs in cows. Cows could have more than 1 case of $\mathrm{CM}$ in the same lactation, but a CM case in the same quarter within $14 \mathrm{~d}$ after a previous case was considered to be the same case. Each observed CM case was recorded by the farmers on a form and was reported on a monthly basis. To ensure high data quality and reduce bias, farmers were reminded by e-mail and telephone to return the forms at the end of each month.

A case of subclinical mastitis (SCM) was defined as a high composite SCC after 2 previous consecutive low composite SCC values, irrespective of the dry period. Threshold values were 150,000 cells/mL for primipa- 
rous and 250,000 cells/mL for multiparous cows (de Haas et al., 2008). Cows could have had more than 1 case of SCM in the same lactation. The incidence rate of SCM (IRSCM) was based on the number of days cows were at risk of developing SCM and was expressed as cases per 100 cows at risk per year in 2013 .

Bulk tank SCC was measured on all farms on a 2-wk basis. These data were used to calculate the average BTSCC for 2013 for each of the farms.

Data were available on all antimicrobials delivered by veterinarians to each of the herds from January 1 to December 31, 2013. The average animal defined daily dose of AMU per year (ADDD/Y; i.e., the average number of days a cow receives antimicrobial treatment) was calculated per herd for 2013 according to the definitions provided by the Dutch Veterinary Medicines Authority (SDa, 2014), as described by Santman-Berends et al. (2015). Antimicrobial use for DCT was calculated as $1 \mathrm{ADDD} / \mathrm{Y}$ per quarter treated with antibiotics at drying-off, as defined by the Dutch Veterinary Medicines Authority (Scherpenzeel et al., 2014).

\section{Statistical Analysis}

The herds were divided into 3 groups, based on the information on the percentage of cows dried off with antibiotics in 2013 as provided during the interviews. The first group applied BDCT (i.e., used DCT on all cows at drying-off). Herds that applied SDCT were split into 2 equally sized groups based on the percentage of cows dried off with antibiotics as indicated by the farmer. The SDCT group with more than median use of dry cow antibiotics was the SDCT high use $\left(\mathbf{S D C T}_{\mathbf{H U}}\right)$ group, and the SDCT group with less than median use of dry cow antibiotics was the SDCT low use $\left(\mathbf{S D C T}_{\mathbf{L U}}\right)$ group.

Descriptive statistics such as means, medians, and percentages were used to describe the complete study population and the 3 study groups $\left(\mathrm{BDCT}, \mathrm{SDCT}_{\mathrm{HU}}\right.$, and $\mathrm{SDCT}_{\mathrm{LU}}$ ). Parameters that were evaluated include herd data, the farmers' mindset, and udder health parameters (IRSCM, IRCM, and BTSCC) in the year 2013. Descriptive statistics and univariable nonparametric tests such as Kruskal-Wallis (Kruskal and Wallis, 1952) and proportion tests were used to evaluate the association between the applied drying-off strategy, AMU, and udder health parameters. Differences between groups with $P \leq 0.05$ were considered significant and differences of groups with a $P$-value between 0.05 and 0.10 were described as a trend.

Defined categories on positive and negative aspects were summed for the groups BDCT, $\mathrm{SDCT}_{\mathrm{HU}}$, and $\mathrm{SDCT}_{\mathrm{LU}}$. For each individual farmer a maximum of 3 positive and 3 negative aspects were included.
In addition, we evaluated whether the farmers' mindset regarding application of DCT was associated with their DCT strategy. For this evaluation, the mindset of the farmers that applied SDCT (groups $\mathrm{SDCT}_{\mathrm{HU}}$ and $\mathrm{SDCT}_{\mathrm{LU}}$ together) were compared with the mindset of farmers that applied BDCT in 2013. Logistic regression models with a logit link function were used for this analysis. Here, the group status was the dependent variable and parameters with regard to the attitude and management of the farmer were included as independent variables. First, the association between group status (BDCT vs. SDCT) and attitude or management variables were prescreened using univariable regression techniques. Variables with a $P$-value $<0.25$ were considered to be potentially associated with the group status and were entered in the multivariable model. The best multivariable model was selected using a stepwise backward selection and elimination procedure. Because of the low number of observations, all parameters with an overall $P$-value $<0.10$ were included in the final model. The best model was deemed to be the model with the Akaike's information criterion closest to 0 (Akaike, 1974). During the selection and elimination procedure, confounding was monitored, and a variable was considered to be a confounder if an estimate of another variable changed by $>20 \%$ after inclusion or exclusion of the (nonsignificant) confounder variable. The amount of variance explained by the final model was evaluated using the pseudo $\mathrm{R}^{2}$. A Pearson goodness-of-fit test was used to evaluate whether the final fitted model was correct. Stata 13.1 (StataCorp, 2014) was used for the analysis.

\section{RESULTS}

\section{Descriptive Results}

Of 233 farmers that enrolled in the study, 177 farmers delivered all requested data and completed the questionnaire. Although udder health parameters of 2 herds were not available, these herds were included in this part of the analysis. In total, 56 farmers did not participate in the interview because they had stopped farming or had switched to organic farming during the study period $(\mathrm{n}=3)$, could not be reached to conduct the questionnaire $(\mathrm{n}=29)$, did not want to cooperate $(\mathrm{n}=19)$, or did not finish the questionnaire (n $=5$ ). The median herd size of the 177 participating herds was 90 lactating cows and varied between 16 and 386 lactating cows. The herds were slightly larger than the average Dutch dairy herd, were representative with regard to their location, purchased slightly more antimicrobials compared with the Dutch average, and 
showed a slightly better udder health based on SCC data (Santman-Berends et al., 2015, 2016).

The median application of DCT was $80 \%$ of cows (mean $72 \%$ ) and varied between all cows (BDCT, $\mathrm{n}=$ 44 herds) and none of the cows ( $\mathrm{n}=2$ herds) in 2013 (Figure 1). The percentage of cows that were dried off with DCT as indicated by the 177 farmers was highest in the first quarter of 2013 (median 95\%) and declined thereafter (second quarter, median $82 \%$; third and fourth quarters, median $80 \%$ ).

Of 177 participants, 44 farmers $(25 \%)$ indicated that they applied BDCT throughout 2013. In the 133 herds in which SDCT was applied, the median percentage of cows that were dried off with antibiotics was $67 \%$ [mean $63 \%$; interquartile range (IQR): 50-87\%], resulting in

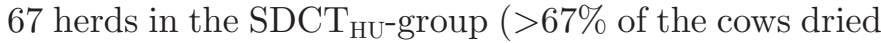
off with antibiotics) and 66 herds in the $\mathrm{SDCT}_{\mathrm{LU}^{-}}$group ( $\leq 67 \%$ of the cows dried off with antibiotics).

The farmers in the SDCT groups used different criteria to select cows for DCT. Often, more than 1 criterion was used. On 93 farms (70\%) SCC history during the complete previous lactation was used, among which 48 farms $(36 \%)$ used SCC at the last milk recording before drying-off. On 36 farms (27\%) CM history in the previous lactation was used, and on 18 farms (14\%) milk yield at the day of dry-off was used as the criterion to select cows for DCT.

When farmers decided to use antimicrobials at drying-off, application of DCT was applied in all 4 quarters by 167 farmers (94\%), whereas 10 farmers (6\%) decided on DCT application at quarter level. In 114 of the 177 herds $(64 \%)$, internal teat sealants were used. Among these 114 herds, 52 farmers $(46 \%)$ used internal teat sealants in all cows, 22 farmers (19\%) in more than $50 \%$ of the cows, and 40 farmers (35\%) in less than $50 \%$ of the cows.

Internal teat sealants at drying-off were more often applied in $\mathrm{SDCT}_{\mathrm{LU}}$ herds (73\%; 95\% CI: $\left.60-83 \%\right)$ compared with herds in which the farmer applied BDCT $(48 \%$; 95\% CI: $32-63 \%)(P$-value $=0.008)$. From the $\mathrm{SDCT}_{\mathrm{HU}}$ group, $64 \%$ (95\% CI: $\left.52-76 \%\right)$ of the farmers applied internal teat sealants at drying-off. This percentage was not different from the $\mathrm{SDCT}_{\mathrm{LU}}$ group and tended to be lower compared with the BDCT group $(P$-value $=0.10)$.

Udder health parameters were available for 175 of the 177 herds. The median IRCM in these herds was 29.1 cases per 100 cows per year (IQR: 21-44; mean 33.7), the median IRSCM was 70.9 cases per 100 cows per year (IQR: 52-86; mean 71.0), and the median BTSCC was 174,000 cells/mL (IQR: 147,000-221,000; mean $183,000)$ in 2013.

Association Between DCT, Mastitis, and $\boldsymbol{A} \boldsymbol{M U}$. The IRCM and IRSCM were comparable be-

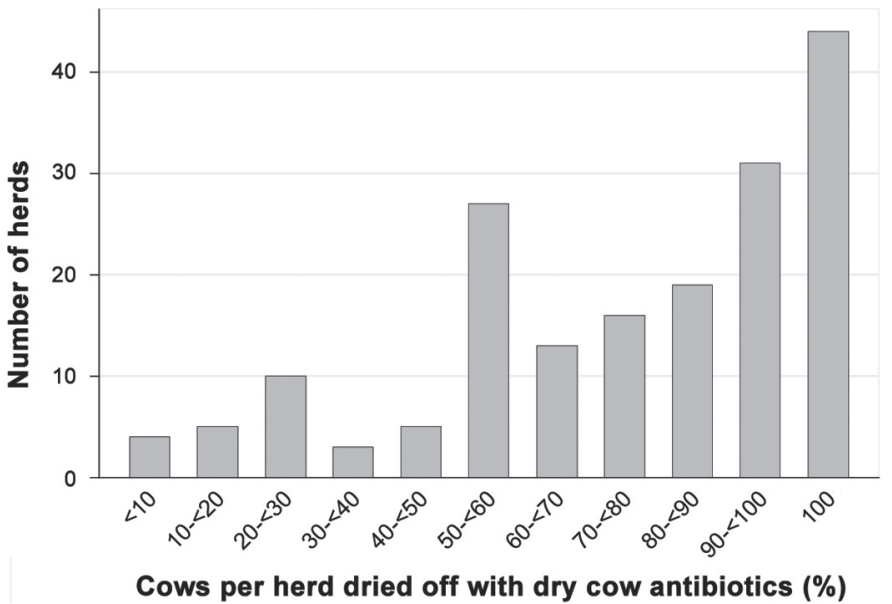

Figure 1. Distribution of the application of dry cow therapy in 177 Dutch dairy herds in 2013.

tween the groups BDCT, $\mathrm{SDCT}_{\mathrm{HU}}$, and $\mathrm{SDCT}_{\mathrm{LU}}(P>$ 0.05; Table 1), but BTSCC tended to be higher in the $\mathrm{SDCT}_{\mathrm{LU}}$ group compared with the $\mathrm{SDCT}_{\mathrm{HU}}$ group $(P=$ $0.08)$ and the BDCT group $(P=0.09)$. Between groups $\mathrm{BDCT}, \mathrm{SDCT}_{\mathrm{HU}}$, and $\mathrm{SDCT}_{\mathrm{LU}}$ a significant difference in total AMU was found, obviously due to a difference in use of dry cow antimicrobials. Group BDCT had 4.48 $\mathrm{ADDD} / \mathrm{Y}$, and groups $\mathrm{SDCT}_{\mathrm{HU}}$ and $\mathrm{SDCT}_{\mathrm{LU}}$ had 4.09 and $3.16 \mathrm{ADDD} / \mathrm{Y}$, respectively. No significant difference in AMU for intramammary or parenteral treatment between the 3 groups was found, although the $\mathrm{SDCT}_{\mathrm{LU}}$ group tended to have a lower ADDD/Y for parenterally applied antimicrobials as compared with the BDCT group (Table 1).

Attitude. The majority (87\%) of farmers agreed or strongly agreed that restricting the use of antimicrobials in the animal industry is important, and $87 \%$ considered they could still be a good farmer when they use antimicrobials less (Table 2). Most of the 177 farmers believed that they select cows for DCT in a correct way (78\% agreed or strongly agreed). Among the interviewed farmers, $53 \%$ indicated having problems with the (potential) negative consequences of SDCT. Most farmers (85\% agreed or strongly agreed) saw their veterinary practitioner as the main advisor with regard to (S)DCT and stated that their veterinarian encouraged them to reduce AMU on their farms (71\% agreed or strongly agreed). Finally, opinions on the experiences of other farmers toward SDCT varied among the interviewees.

Most farmers cited "financial consequences" and "improving public health" within the top 3 most positive aspects of reducing AMU (Table 3). No significant differences existed in the most important positive aspects of reduction of AMU between the 3 groups. 
Table 1. Udder health parameters and antimicrobial use for 3 groups of dairy herds with different proportions of cows dried off with antibiotics ${ }^{1}$

\begin{tabular}{|c|c|c|c|}
\hline Item & $\begin{array}{c}\mathrm{BDCT} \\
(\mathrm{n}=44)\end{array}$ & $\begin{array}{l}\mathrm{SDCT}_{\mathrm{HU}} \\
(\mathrm{n}=67)\end{array}$ & $\begin{array}{l}\mathrm{SDCT}_{\mathrm{LU}} \\
(\mathrm{n}=66)\end{array}$ \\
\hline Incidence rate of clinical mastitis/100 cows per year ${ }^{2}$ & $28(22-44)$ & $30(21-44)$ & $30(19-42)$ \\
\hline $\mathrm{ADDD} / \mathrm{Y}$ total $(\text { cows }>2 \mathrm{yr} \text { old })^{3^{3}}$ & $4.48^{\mathrm{a}}$ & $4.09^{\mathrm{b}}$ & $3.16^{\mathrm{c}}$ \\
\hline ADDD/Y dry cow treatment & $1.98^{\mathrm{a}}$ & $1.65^{\mathrm{b}}$ & $0.92^{\mathrm{c}}$ \\
\hline ADDD/Y intramammary treatment ${ }^{4}$ & 0.70 & 0.52 & 0.63 \\
\hline
\end{tabular}

${ }^{\mathrm{a}-c}$ Values within a row with different superscripts are statistically different $(P \leq 0.05)$.

${ }^{1}$ Farmers were categorized in groups with blanket dry cow therapy $(\mathrm{BDCT}, 100 \% \mathrm{DCT})$, selective dry cow therapy high use $\left(\mathrm{SDCT} \mathrm{HU}_{\mathrm{HU}}>67 \%\right.$ DCT and $<100 \%$ DCT), and selective dry cow therapy low use ( $\left.\mathrm{SDCT}_{\mathrm{LU}}, \leq 67 \% \mathrm{DCT}\right)$.

${ }^{2}$ Values are medians $(25-75$ th percentile).

${ }^{3} \mathrm{ADDD} / \mathrm{Y}=$ animal defined daily dose of antimicrobial use per year.

${ }^{4}$ Intramammary treatment other than dry cow treatment.

With respect to the negative consequences of reducing AMU, significant differences were found in the indicators between the 3 evaluated groups of herds. Eleven percent of the farmers could not name a single negative aspect of reducing AMU. Overall, $25 \%$ of the farmers considered "uncertainty whether a cow will recover without antimicrobials" and a "higher risk of sick cows" as the most important negative aspects of reducing AMU, followed by farmers who indicated that "cows suffer without antimicrobials" (17\%). Some farmers answered that they believed that reducing AMU would lead to additional labor $(14 \%)$ or had the feeling they were being pushed to follow rules that they do not agree with (14\%).

Farmers that applied BDCT or $\mathrm{SDCT}_{\mathrm{HU}}$ were significantly more often uncertain whether a cow would recover without antimicrobials as compared with farmers in the $\mathrm{SDCT}_{\mathrm{LU}}$ group (41 and $30 \%$ vs. $9 \%$; $P$-value $<$ 0.001 and 0.003 , respectively). In addition, farmers in the $\mathrm{SDCT}_{\mathrm{HU}}(4 \%)$ and $\mathrm{SDCT}_{\mathrm{LU}}(6 \%)$ groups considered "financial consequences" significantly less frequently as one of the most important negative aspects of reducing
AMU compared with the BDCT group (18\%) ( $P$-value 0.05 and 0.02 , respectively). Finally, farmers of the $\mathrm{SDCT}_{\mathrm{HU}}$ group indicated worries about animal health as one of the most important negative aspects of AMU significantly more often (9\%) when compared with $\operatorname{SDCT}_{\mathrm{LU}}(0 \%)$ herds (P-value 0.01) (Table 4).

Multivariable Analysis. Of the 29 variables that were evaluated (28 variables related to attitude and 1 management variable related to usage of internal teat sealants), 9 variables had a $P$-value $<0.25$ in the univariable prescreening. These variables were shown to be potentially associated with DCT and therefore were entered in the multivariable model (BDCT versus SDCT).

The final multivariable model contained 3 variables based on the mindset of the farmer and 1 variable based on the usage of internal teat sealants. The final model had the lowest possible Akaike's information criterion (178), showed no evidence of incorrectness of the fitted model $(P$-value $=0.20)$, and explained $19 \%$ of the variation in application of BDCT and SDCT (pseudo $\left.\mathrm{R}^{2}=0.19\right)$. Farmers who indicated that the financial

Table 2. Opinions (number with $\%$ in parentheses) of 177 dairy farmers on statements toward antibiotic usage in the animal industry and toward dry cow therapy

\begin{tabular}{|c|c|c|c|c|c|}
\hline Item & $\begin{array}{l}\text { Strongly } \\
\text { disagree }\end{array}$ & Disagree & $\begin{array}{l}\text { Neither agree } \\
\text { nor disagree }\end{array}$ & Agree & $\begin{array}{l}\text { Strongly } \\
\text { agree }\end{array}$ \\
\hline $\begin{array}{l}\text { It is important that the usage of antimicrobials in the animal industry is } \\
\text { restricted. }\end{array}$ & $7(4)$ & $2(1)$ & $13(7)$ & $24(13)$ & $133(74)$ \\
\hline My veterinarian encourages me to reduce antibiotic usage on my farm. & $18(10)$ & $9(5)$ & $26(15)$ & $23(13)$ & $103(58)$ \\
\hline $\begin{array}{l}\text { I do not have a problem with the (potential) negative consequences of selective } \\
\text { dry cow therapy. }\end{array}$ & $66(37)$ & $28(16)$ & $21(12)$ & $20(11)$ & $44(25)$ \\
\hline Other dairy farmers I know are positive about selective dry cow therapy. & $28(16)$ & $17(10)$ & $89(50)$ & $18(10)$ & $27(15)$ \\
\hline
\end{tabular}


Table 3. The most important (top 3) positive aspects of the reduction of antimicrobial usage according to 177 Dutch dairy farmers, expressed in percentages (95\% CI in parentheses) ${ }^{1}$

\begin{tabular}{|c|c|c|c|c|}
\hline Item & $\begin{array}{c}\text { Overall } \\
(\mathrm{n}=177)\end{array}$ & $\begin{array}{c}\text { BDCT } \\
(\mathrm{n}=44)\end{array}$ & $\begin{array}{l}\mathrm{SDCT}_{\mathrm{HU}} \\
(\mathrm{n}=67)\end{array}$ & $\begin{array}{l}\mathrm{SDCT}_{\mathrm{LU}} \\
(\mathrm{n}=66)\end{array}$ \\
\hline Financial consequences & $46(38-53)$ & $52(37-68)$ & $40(29-53)$ & $48(36-61)$ \\
\hline Easier to take care of my dairy herd & $13(8-19)$ & $16(7-30)$ & $7(3-17)$ & $17(9-28)$ \\
\hline Creating resilient cows & $13(8-19)$ & $7(1-19)^{\mathrm{a}}$ & $10(4-20)^{\mathrm{ab}}$ & $20(11-31)^{\mathrm{b}}$ \\
\hline Less withholding of milk and meat & $11(7-16)$ & $14(5-27)$ & $9(3-19)$ & $12(5-23)$ \\
\hline
\end{tabular}

$\overline{a, b}$ Values within a row with different superscripts are statistically different $(P<0.10)$.

${ }^{1}$ Farmers were categorized in groups with blanket dry cow therapy (BDCT, $100 \%$ DCT), selective dry cow therapy high use $\left(\mathrm{SDCT}_{\mathrm{HU}},>67 \%\right.$ DCT and $<100 \%$ DCT), and selective dry cow therapy low use $\left(\mathrm{SDCT}_{\mathrm{LU}}, \leq 67 \% \mathrm{DCT}\right)$.

consequence was one of the most important negative aspects of reducing AMU had a 4.7 times higher odds $(95 \%$ CI: $1.4-16.0, P$-value $=0.01)$ of applying BDCT instead of SDCT compared with farmers that did not indicate this negative aspect. In addition, farmers that indicated uncertainty about whether a cow will recover without antimicrobials as one of the most important negative aspects of reducing AMU had a 3.0 times higher odds (95\% CI: $1.3-7.0 ; P$-value $=0.009)$ of applying BDCT instead of SDCT. Farmers that either strongly disagreed or were neutral with regard to the statement "I do not have a problem with the (potential) negative consequences of selective dry cow therapy" had significantly higher odds of applying BDCT compared with farmers that strongly agreed with this statement (odds ratio $=4.1,95 \%$ CI: $1.1-15.7$ and odds ratio $=$ 10.5, 95\% CI: 2.3-48.2, respectively). Finally, use of internal teat sealants at drying-off was associated with a 2.1 times lower odds (95\% CI: $0.9-4.5, P$-value $=0.07)$ of applying BDCT compared with no use of internal teat sealants at drying-off.

\section{DISCUSSION}

The aim of this study was to provide insight into the level of SDCT implementation and the methods used for implementation of SDCT in 2013 in the Netherlands. Furthermore, SDCT in relation to udder health indicators, AMU, and the attitude and motivation of farmers toward SDCT were evaluated. The results showed that Dutch farmers took up SDCT progressively, with $75 \%$ of them implementing a form of SDCT in 2013. During this year, increasingly more farmers began with SDCT, although no implementation guideline existed. No dramatic increase in mastitis incidence and related AMU occurred with implementation of SDCT, although earlier work had shown a possible increase in IRCM and SCM when SDCT was applied (Scherpenzeel et al., 2014; Cameron et al., 2015). This difference may be due to these studies using more stringent criteria for DCT, such as SCC at the last milk recording before drying-off and on-farm culturing as criteria to select cows for DCT. Additionally, in the earlier studies only

Table 4. The most important (top 3) negative aspects of the reduction of antimicrobial usage according to 177 Dutch dairy farmers, expressed in percentages $\left(95 \%\right.$ CI in parentheses) ${ }^{1}$

\begin{tabular}{|c|c|c|c|c|}
\hline Item & $\begin{array}{c}\text { Overall } \\
(\mathrm{n}=177)\end{array}$ & $\begin{array}{c}\mathrm{BDCT} \\
(\mathrm{n}=44)\end{array}$ & $\begin{array}{l}\mathrm{SDCT}_{\mathrm{HU}} \\
(\mathrm{n}=67)\end{array}$ & $\begin{array}{l}\mathrm{SDCT}_{\mathrm{LU}} \\
(\mathrm{n}=66)\end{array}$ \\
\hline Uncertainty whether a cow will recover without antimicrobials & $25(19-32)$ & $41(26-57)^{\mathrm{a}}$ & $30(19-42)^{\mathrm{a}}$ & $9(3-19)^{\mathrm{b}}$ \\
\hline Extra labor & $14(9-20)$ & $16(7-30)$ & $16(8-27)$ & $9(3-19)$ \\
\hline Pushed to follow the rules, although I do not agree with the policy & $14(9-20)$ & $9(3-22)$ & $16(8-27)$ & $14(6-24)$ \\
\hline Risk of making the wrong choice about whether to treat & $10(6-15)$ & $11(4-25)$ & $10(4-20)$ & $8(3-17)$ \\
\hline Worries about animal health & $4(2-8)$ & $2(0-12)^{\mathrm{ab}}$ & $9(3-18)^{\mathrm{a}}$ & $0(0-4)^{b}$ \\
\hline Harder to take care of my dairy herd & $2(1-6)$ & $2(0-12)$ & $1(0-8)$ & $3(0-11)$ \\
\hline
\end{tabular}

${ }^{\mathrm{a}, \mathrm{b}}$ Values within a row with different superscripts are statistically different $(P \leq 0.05)$.

${ }^{1}$ Farmers were categorized in groups with blanket dry cow therapy (BDCT, 100\% DCT), selective dry cow therapy high use $\left(\mathrm{SDCT}_{\mathrm{HU}},>67 \%\right.$ DCT and $<100 \%$ DCT), and selective dry cow therapy low use $\left(\mathrm{SDCT}_{\mathrm{LU}}, \leq 67 \% \mathrm{DCT}\right)$. 
low SCC cows were considered, whereas in the current study all cows were included. Farmers may be aware of this greater risk of CM and may have changed their udder health management as well.

Our study showed that farmers selected their cows mostly based on SCC history and CM history. These criteria are in line with findings that were described earlier by Torres et al. (2008) and Rajala-Schultz et al. (2011) and are considered useful parameters in practice.

The belief of farmers whether SDCT will result in an increased risk for $\mathrm{CM}$ influences their choice to apply either BDCT or SDCT. Individual positive or negative experiences with the use of SDCT are obviously of great importance for their beliefs. In our study we found that farmers' attitude explained $19 \%$ of the variation in applying BDCT or SDCT, which is higher than the percentage of explained variance in udder health based on management parameters (van den Borne et al., 2010; Santman-Berends et al., 2016). This finding was described earlier by Jansen et al. (2010), who found that farmers' mindset is highly associated with udder health. Furthermore, a study on prudent antibiotic use in South Carolina showed that mindset-related factors such as limited economic benefits and lack of time were barriers to following proper antibiotic procedures (Friedman et al., 2007). These factors appeared to influence the mindset of Dutch dairy farmers as well because financial consequences were mentioned as one of the most important positive aspects. In addition to factors related to farmers' attitude, we also found that application of internal teat sealants at drying-off were applied more often in herds for which the farmer applied SDCT compared with herds for which the farmer applied BDCT. Usage of internal teat sealants was previously found to have a protective effect on the incidence of new CM cases because teat sealants help prevent colonization of quarters with bacteria during the dry period (Rabiee and Lean, 2013).

This questionnaire, executed in April and May 2014, included questions regarding the attitude of the farmer and the management of the herd in 2013. Hence, some recall bias may have been present because interviewees may have been unable to remember the decisions they made regarding dry cow management. However, the attitude of farmers does not change quickly (Hardeman et al., 2002), so it can be assumed that the attitudes measured in the current study had not changed tremendously between the year 2013 and the moment the questionnaire was conducted.

In our study, farmers indicated that on average $72 \%$ of the cows were dried off with dry cow antibiotics. This percentage is higher than the $61 \%$ estimated in the study of Santman-Berends et al. (2016). The dif- ference between these percentages can be explained by the differences in data that were used in the 2 studies. In our current study, we used the information from the farmers on usage of antimicrobials for DCT as indicated in the questionnaire, but Santman-Berends et al. (2016) used the data on supplies of antimicrobials for DCT. Both estimates are imperfect. In the earlier report (Santman-Berends et al., 2016), antimicrobial supplies from the veterinarian to the farmer were used, which is a proxy for AMU and does not provide data on the actual usage. In addition, the percentage as described by Santman-Berends et al. (2016) slightly underestimated the percentage of cows in which DCT was applied because it was assumed that antimicrobials were applied in all 4 quarters. In our current analysis we found that $6 \%$ of farmers do not treat all quarters when they use antimicrobials at drying-off.

In this study, farmers that indicated using BDCT likely reported that information correctly. Some recall bias might have occurred for herds in which SDCT was applied. This possible bias was also supported by the results presented in Figure 1 in which a relatively high number of farmers answered that they applied DCT in $50 \%$ of the cows. The only way to have exact data on the use of dry cow antimicrobials would have been by individual registration of DCT. This type of information was, however, not available in this study. Although recall bias might have occurred in the SDCT groups, we believe that it did not substantially influence the allocation of farms to the DCT groups. The cut-off value between SDCT groups was set at $67 \%$, with most $\mathrm{SDCT}_{\mathrm{LU}}$ herds having a SDCT of $50 \%$ or less and antimicrobials being used at drying-off in $80 \%$ or more of the cows in these herds.

Multivariable analysis was carried out to find significant differences between the BDCT and SDCT groups. Farmers that either strongly disagreed or were neutral with regard to the statement "I do not have a problem with the (potential) negative consequences of SDCT" had significantly higher odds of applying BDCT compared with farmers that strongly agreed with this statement (odds ratio $=4.1 ; 95 \%$ CI: $1.1-15.7$ ). If the $\mathrm{SDCT}_{\mathrm{HU}}$ had not been taken into account in the multivariable analysis, the odds would be much higher and increase to 13.7 in the comparison of BDCT to $\mathrm{SDCT}_{\mathrm{LU}}$. We chose to keep the $\mathrm{SDCT}_{\mathrm{HU}}$ group in the analysis to compare all 3 groups over all aspects.

Our results show that the application of SDCT is associated with farmers' attitude. Specific attention given to SDCT in education, training, and specific campaigns seems important to changing farmers' attitude toward mastitis management (Lam et al., 2013). Additionally, efforts need to be made to support the farmer in reduc- 
ing the risk of mastitis by improving mastitis management in general and providing effective measures for mastitis prevention.

\section{CONCLUSIONS}

Selective DCT was quickly adopted by the farmers in our study, with $75 \%$ of them implementing SDCT in 2013. The main criterion used to select cows for DCT was the SCC history during the complete previous lactation. No significant differences were found in udder health parameters between herds in which BDCT or SDCT was applied or between SDCT herds with high or low DCT use. Overall, AMU was higher in herds in which BDCT was applied, although no significant differences existed in intramammary use of antimicrobials. Although application of SDCT appeared to be associated with farmers' attitude, the mindset of farmers with respect to reducing $\mathrm{AMU}$ in general and implementing SDCT seemed positive.

\section{ACKNOWLEDGMENTS}

This study was financially supported by the Dutch Dairy Board (ZuivelNL, Zoetermeer, the Netherlands). The authors appreciate the cooperation of the dairy farmers involved in this study.

\section{REFERENCES}

Akaike, H. 1974. A new look at the statistical model identification. IEEE Trans. Automat. Contr. 19:716-723.

Cameron, M., G. P. Keefe, J. P. Roy, H. Stryhn, I. R. Dohoo, and S. L. McKenna. 2015. Evaluation of selective dry cow treatment following on-farm culture: Milk yield and somatic cell count in the subsequent lactation. J. Dairy Sci. 98:2427-2436.

Chantziaras, I., F. Boyen, B. Callens, and J. Dewulf. 2014. Correlation between veterinary antimicrobial use and antimicrobial resistance in food-producing animals: A report on seven countries. J. Antimicrob. Chemother. 69:827-834.

de Haas, Y., W. Ouweltjes, J. ten Napel, J. J. Windig, and G. de Jong. 2008. Alternative somatic cell count traits as mastitis indicators for genetic selection. J. Dairy Sci. 91:2501-2511.

Freimuth, V., H. W. Linnan, and P. Potter. 2000. Communicating the threat of emerging infections to the public. Emerg. Infect. Dis. $6: 337-347$.

Friedman, D. B., C. P. Kanwat, M. L. Headrick, N. J. Patterson, J. C. Neely, and L. U. Smith. 2007. Importance of prudent antibiotic use on dairy farms in South Carolina: A pilot project on farmers' knowledge, attitudes and practices. Zoonoses Public Health 54:366-375.

Hardeman, W., M. Johnston, D. W. Johnston, D. Bonetti, N. J. Wareham, and A. L. Kinmonth. 2002. Application of the theory of planned behavior in behaviour change interventions: A systematic review. Psychol. Health 17:123-158.

Jansen, J., R. J. Renes, and T. J. G. M. Lam. 2010. Evaluation of two communication strategies to improve udder health management. J. Dairy Sci. 93:604-612.
Jones, P. J., E. A. Marier, R. B. Tranter, G. Wu, E. Watson, and C. J. Teale. 2015. Factors affecting dairy farmers' attitudes towards antimicrobial medicine usage in cattle in England and Wales. Prev. Vet. Med. 121:30-40.

KNMvD. 2014. Guidelines for the use of antimicrobials for drying off milking cows (in Dutch). Accessed Feb. 21, 2016. https://www. knmvd.nl/media/default.aspx/emma/org/10837091/richtlijn\%20 droogzetten $\% 20$ melkkoeien.pdf.

Kruskal, W. H., and W. A. Wallis. 1952. Use of ranks in one-criterion variance analysis. J. Am. Stat. Assoc. 47:583-621.

Kuipers, A., W. J. Koops, and H. Wemmenhove. 2016. Antibiotic use in dairy herds in the Netherlands from 2005 to 2012. J. Dairy Sci. 99:1632-1648.

Lam, T. J. G. M., J. Jansen, B. H. P. van den Borne, R. J. Renes, and H. Hogeveen. 2011. What veterinarians need to know about communication to optimise their role as advisors on udder health in dairy herds. N. Z. Vet. J. 59:8-15.

Lam, T. J. G. M., B. H. P. van den Borne, J. Jansen, K. Huijps, J. C. van Veersen, G. van Schaik, and H. Hogeveen. 2013. Improving bovine udder health: A national mastitis control program in the Netherlands. J. Dairy Sci. 96:1301-1311.

Likert, R. 1932. A technique for the measurement of attitudes. Arch. Psychol. 22:1-55

Oliver, S. P., S. E. Murinda, and B. M. Jayarao. 2011. Impact of antibiotic use in adult dairy cows on antimicrobial resistance of veterinary and human pathogens: A comprehensive review. Foodborne Pathog. Dis. 8:337-355.

Rabiee, A. R., and I. J. Lean. 2013. The effect of internal teat sealant products (Teatseal and Orbeseal) on intramammary infection, clinical mastitis, and somatic cell counts in lactating dairy cows: A meta-analysis. J. Dairy Sci. 96:6915-6931.

Rajala-Schultz, P. J., A. H. Torres, and F. J. Degraves. 2011. Milk yield and somatic cell count during the following lactation after selective treatment of cows at dry-off. J. Dairy Res. 78:489-499.

Sampimon, O. C., R. G. M. Olde Riekerink, and T. J. G. M. Lam. 2008. Prevalence of subclinical mastitis pathogens and adoption of udder health management practices on Dutch dairy farms: Preliminary results. Pages 39-46 in Proc. Mastitis Control: From Science to Practice, The Hague, the Netherlands. Wageningen Academic Publishers, Wageningen, the Netherlands.

Santman-Berends, I. M. G. A., T. J. G. M. Lam, J. Keurentjes, and G. van Schaik. 2015. An estimation of the clinical mastitis incidence per 100 cows per year based on routinely collected herd data. J. Dairy Sci. 98:6965-6977.

Santman-Berends, I. M. G. A.. J. M. Swinkels, T. J. G. M. Lam, J. Keurentjes, and G. van Schaik. 2016. Evaluation of udder health parameters and risk factors for clinical mastitis in Dutch dairy herds in the context of a restricted antimicrobial usage policy. J. Dairy Sci. 99:2930-2939.

Scherpenzeel, C. G. M., I. E. M. den Uijl, G. van Schaik, R. G. M. Olde Riekerink, J. M. Keurentjes, and T. J. G. M. Lam. 2014 Evaluation of the use of dry cow antibiotics in low somatic cell count cows. J. Dairy Sci. 97:3606-3614.

SDa. 2014. Usage of antibiotics in agricultural livestock in the Netherlands in 2013. Accessed Feb. 4, 2016. http://www. autoriteitdiergeneesmiddelen.nl/en/publications.

StataCorp. 2014. Stata Software version 13. StataCorp, College Station, TX.

Torres, A. H., P. J. Rajala-Schultz, F. J. Degraves, and K. H. Hoblet. 2008. Using dairy herd improvement records and clinical mastitis history to identify subclinical mastitis infections at dry-off. J. Dairy Res. 75:240-247.

van den Borne, B. H. P., G. van Schaik, T. J. G. M. Lam, and M. Nielen. 2010. Variation in herd level mastitis indicators between primiand multiparae in Dutch dairy herds. Prev. Vet. Med. 96:49-55. 